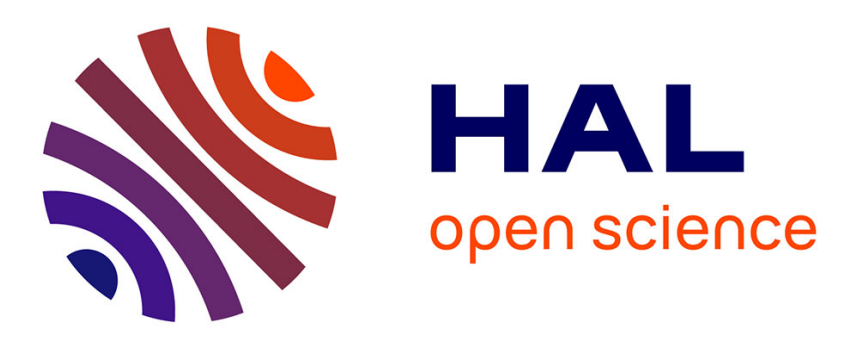

\title{
Biodistribution of PVP-hypericin and hexaminolevulinate-induced PpIX in normal and orthotopic tumor-bearing rat urinary bladder
}

Joachim Vandepitte, Ben Cleynenbreugel, Klaudia Hettinger, Hendrik Poppel, Peter A. M. Witte

\section{To cite this version:}

Joachim Vandepitte, Ben Cleynenbreugel, Klaudia Hettinger, Hendrik Poppel, Peter A. M. Witte. Biodistribution of PVP-hypericin and hexaminolevulinate-induced PpIX in normal and orthotopic tumor-bearing rat urinary bladder. Cancer Chemotherapy and Pharmacology, 2010, 67 (4), pp.775781. 10.1007/s00280-010-1375-0 . hal-00599221

\section{HAL Id: hal-00599221 \\ https://hal.science/hal-00599221}

Submitted on 9 Jun 2011

HAL is a multi-disciplinary open access archive for the deposit and dissemination of scientific research documents, whether they are published or not. The documents may come from teaching and research institutions in France or abroad, or from public or private research centers.
L'archive ouverte pluridisciplinaire HAL, est destinée au dépôt et à la diffusion de documents scientifiques de niveau recherche, publiés ou non, émanant des établissements d'enseignement et de recherche français ou étrangers, des laboratoires publics ou privés. 


\title{
Biodistribution of PVP-hypericin and hexaminolevulinate-induced PpIX in normal and orthotopic tumor bearing rat urinary bladder
}

Vandepitte, $\mathrm{J}^{1}$, Van Cleynenbreugel, $\mathrm{B}^{2}$, Hettinger $\mathrm{K}^{3}$, Van Poppel, $\mathrm{H}^{2}$, de Witte, $\mathrm{PAM}^{1}$

1 Laboratory for Pharmaceutical Biology, Faculty of Pharmaceutical sciences, Katholieke Universiteit Leuven, B-3000, Leuven, Belgium

2 Department of Urology, University Hospital Leuven, B-3000, Leuven, Belgium

${ }^{3}$ Sanochemia Pharmazeutika AG, 1090 Vienna, Austria

To whom correspondence should be addressed at: Laboratorium voor Farmaceutische Biologie, Faculteit Farmaceutische Wetenschappen, Katholieke Universiteit Leuven, Herestraat 49, bus 824, B-3000 Leuven, Belgium

Phone: 32-16-323432

Fax: $32-16-323460$

E-mail: peter.dewitte@pharm.kuleuven.be

\author{
Abbreviations: \\ PVP: Polyvinylpyrrolidone \\ HAL: Hexaminolevulinate \\ PpIX: protoporphyrin IX \\ DiO: 3,3'-dioctadecyloxacarbocyanine perchlorate \\ H\&E: Hematoxylin and eosin \\ NMIBC: non-muscle invasive bladder cancer
}




\section{Abstract}

\section{Purpose}

In this preclinical study we examined the biodistribution of hypericin formulated as its watersoluble PVP-hypericin complex in the different layers (urothelium, submucosa, muscle) of a normal rat bladder and a rat bladder bearing a malignant urothelium composed of syngeneic AY27 tumor cells. The results were compared with the biodistribution of hexaminolevulinate (HAL) induced protoporphyrin IX (PpIX).

\section{Methods}

Freshly prepared PVP-hypericin and HAL solutions were instilled in both normal as well as tumor bearing rat bladders. Following instillation, bladders were removed and snap frozen in liquid nitrogen. Fluorescence of PVP-hypericin or PpIX induced HAL was measured in the bladder layers and quantified using image analysis software.

\section{Results}

The results of these experiments show that PVP-hypericin $(30 \mu \mathrm{M})$ accumulated about 3.5fold more in malignant urothelial tissue as compared to normal urothelium, whereas PpIX accumulated to the same extent in malignant and normal urothelium, both after intra-bladder instillation of 8 or $16 \mathrm{mM} \mathrm{HAL}$. Besides, PVP-hypericin and PpIX accumulated selectively in the urothelium with a tumor-to-muscle ratio of 30.6 for PVP-hypericin and 3.7 to 8.3 for 16 and $8 \mathrm{mM}$ HAL, respectively.

\section{Conclusions}

This study shows that PVP-hypericin appears to have great potential as a photodynamic agent against non-muscle invasive bladder cancers after intravesical administration, with a limited risk of affecting the deeper layers of the bladder.

Keywords: Bladder cancer, orthotopic animal model, PVP-hypericin, HAL 


\section{Introduction}

Urinary bladder cancer is the fifth most frequent type of cancer in western world [1]. When first diagnosed, $75-85 \%$ of these bladder tumors are staged as non-muscle-invasive bladder cancers (NMIBC), which are generally treated by transurethral resection with or without adjuvant intravesical chemotherapy or immunotherapy $[2,3]$.

During the last decade several compounds have been tested for their capacity to photodiagnose efficiently malignant bladder lesions, and by doing so to reduce the amount of recurrences after transurethral resection of the bladder [4,5]. One of the compounds used is hypericin, a fluorescent photosensitizer that belongs to the chemical class of hydroxylated phenantroperylenequinones [6,7]. After intrabladder instillation in patients suspected of having bladder cancer, hypericin showed a very good sensitivity and specificity for detecting NMIBC, including carcinoma in situ (CIS) [8-10]. The finding that hypericin is selectively taken up by urothelial tumor cells and not by normal cells is also supported by clinical studies using fluorescence cytology [11,12].

In water hypericin forms aggregates, thereby loosing its spectroscopic and tumor-selective properties [13]. In previous studies, this problem was overcome by including plasma proteins like human serum albumin (HSA) into the formulation to which hypericin adsorbs [8,9]. More recently, with the intention to avoid the presence of proteins in the bladder instillation fluid, a novel formulation was developed based on a water-soluble complex formed between hypericin and polyvinylpyrrolidone (PVP) [14,15].

5-Aminolevulinic acid (5-ALA) is another compound that is being used for fluorescence cystoscopy of the bladder. Its use in urology was first described by Leveckis et al. [16]. Exogenous administration of 5-ALA induces a transient rise in the cellular concentration of the fluorescent PpIX, which is more pronounced in neoplastic cells than in normal cells $[17,18]$. An ester precursor of 5-ALA, i.e. hexaminolevulinate (HAL) provides an even better selectivity and brighter fluorescence as compared to the parent compound. Using fluorescence cystoscopy in combination with intrabladder HAL, it was shown that $28 \%$ more patients with $\mathrm{CIS}$ were identified than with the standard cystoscopy method [19]. Hexaminolevulinate (Hexvix®, Photocure ASA) has recently obtained a marketing authorization in 27 European countries, including Norway and Iceland, for the improved detection of superficial bladder cancer [20].

Hypericin and ALA-induced PpIX do not only exhibit red fluorescence upon blue light irradiation, both compounds are also potent photosensitizers and hence could be useful in the photodynamic therapy (PDT) of NMIBC after intrabladder instillation [21-23]. PDT for cancer involves the local or systemic administration of a photosensitizer followed by local irradiation of 
the tumor tissue with non-thermal visible light of a specific wavelength. The local generation of ROS (reactive oxygen species) by the irradiated photosensitizer results in tumor destruction $[7,24]$.

Anticipating the clinical use of PVP-hypericin in the therapeutic management of NMIBC, it is essential to understand the selectivity of the accumulation of the photosensitizer into urothelial malignant lesions. In order to avoid any damage, it is critical that the compound does not accumulate substantially into the deeper layers of the bladder wall, especially in the detrusor muscle.

This preclinical study examined the biodistribution of hypericin formulated as its water-soluble PVP-hypericin complex (hereafter called PVP-hypericin) in the different layers (urothelium, submucosa, muscle) of a normal rat bladder and a rat bladder bearing a malignant urothelium composed of syngeneic AY-27 tumor cells [25]. The results were compared with the outcome using HAL in similar in vivo conditions. As there is a very limited penetration into the deeper layers of the bladder, we anticipate that PVP-hypericin is a safe compound when it will be used for intravesical instillation followed by whole bladder wall photodynamic therapy 


\section{Materials and methods}

Animals

For all experiments female Fisher rats (F-344), weighing a minimum of $160 \mathrm{~g}$, were used (Charles River Laboratories, Lyon, France). Rats were provided with purine chow and water ad libitum. All animal procedures were performed in compliance with national and European regulations and were approved by the animal care and ethics committee of the Katholieke Universiteit Leuven.

Preparation of cells for tumor implantation

AY-27 cells, originally developed by Dr. S. Selman and Dr. J. Hampton (Ohio Medical College, USA), were kindly provided by Dr. D. Notter (Université henri Poincare, Nancy, France). Cells were cultured in $175 \mathrm{~cm}^{2}$ tissue culture flasks at $37^{\circ} \mathrm{C}$ in a humidified atmosphere containing $5 \% \mathrm{CO}_{2}$ and $95 \%$ air in Minimum Essential Medium (MEM) with Earle's salts containing $2 \mathrm{mM} \mathrm{L-glutamine,} \mathrm{1 \%} \mathrm{antibiotic/antimycotic} \mathrm{solution,} \mathrm{1 \%} \mathrm{non-essential} \mathrm{amino} \mathrm{acids,}$ tylosine $(60 \mu \mathrm{g} / \mathrm{ml})$ (Eli Lilly, Brussels, Belgium) and 10\% foetal calf serum (FCS). All cell culture medium compounds were purchased from Invitrogen (Merlebeke, Belgium).

AY-27 cells were cultured until confluency and then incubated for 30 min with $20 \mu \mathrm{M}$ green fluorescent cell tracker 3,3'-dioctadecyloxacarbocyanine (DiO). DiO was purchased from Molecular Probes Inc. (Eugene, OR, USA) and stored as a $20 \mathrm{mM}$ stock solution in DMSO at $20^{\circ} \mathrm{C}$. Just before use, the stock solution was diluted in MEM to obtain a concentration of $20 \mu \mathrm{M}$. Afterwards, cells were washed twice with PBS ( $\mathrm{pH} 7.4)$, trypsinized and collected after centrifugation (2000 rpm, 5 min, Jouan B3.11; St. Nazaire, France). Cells were counted using a Coulter Z1 particle counter (Coulter Electronic, Luton, UK) and resuspended in cell culture medium to obtain a concentration of $4 \times 10^{6}$ cells $/ 0.3 \mathrm{ml}$.

\section{Tumor model}

The technique used for tumor implantation was described previously ([26] with modification). Animals were anesthetized with an intraperitoneal injection of $45 \mathrm{mg} / \mathrm{kg}$ sodium pentobarbital (Nembutal) and placed on supine position on an animal board kept at $25^{\circ} \mathrm{C}$. Bladders were catheterized via the urethra using a plastic 18 gauge intravenous catheter. Subsequently, the bladder mucosa was mildly disrupted using a wash with $0.3 \mathrm{ml}$ of $0.1 \mathrm{~N} \mathrm{HCl}$ for 20 seconds, followed by neutralization with the same quantity and strength of $\mathrm{NaOH}$ for 20 seconds. The bladder was then washed several times thoroughly with PBS. AY- 27 cells $\left(4 \times 10^{6}\right.$ cells in $0.3 \mathrm{ml}$ of medium) loaded with $\mathrm{DiO}$ were instilled into the bladder via the catheter and maintained in the bladder for at least $1 \mathrm{~h}$. Rats were turned by $45^{\circ}$ every $15 \mathrm{~min}$ to allow equal exposure of tumor cells to the entire bladder wall. Thereafter, the cannula was removed and the rats were allowed to 
void spontaneously. Animals were used for bladder wall distribution studies of the photosensitizers three days later.

Intrabladder instillation of PVP-hypericin and HAL

Rats were anesthetized with sodium pentobarbital (Nembutal, $45 \mathrm{mg} / \mathrm{kg}$, i.p.) and after catheterization, $0.3 \mathrm{ml}$ of a freshly prepared PVP-hypericin instillation fluid $(30 \mu \mathrm{M}$ in $0.9 \% \mathrm{NaCl})$ (Provided by Sanochemia Pharmazeutika AG) or HAL (8 and $16 \mathrm{mM}$, prepared in phosphate buffered saline according to [27] ) (GE-Healthcare) were instilled in normal and in tumor bearing bladders for $2 \mathrm{~h}$ ( $\mathrm{n}=6$ per condition). Control animals $(\mathrm{n}=3)$ were instilled with saline only. Afterwards bladders were removed, cut open and immediately transferred into Tissue Tek embedding medium (Miles Inc., Elkhart, IN, USA) and immersed in liquid nitrogen. Cryostat microtomy was performed to cut $5 \mu \mathrm{m}$ sections.

Imaging and quantification of fluorescence

Imaging and quantification of fluorescence in sections of normal bladder and tumor bearing bladders were performed by the use of a fluorescence microscope equipped with image analysis software. The microscope consisted of an Axioskop 2 plus fluorescence microscope (Carl Zeiss, Göttingen, Germany) illuminated by a $100 \mathrm{~W}$ mercury lamp. Fluorescence images were acquired using a light-sensitive charge-coupled device (CCD) digital camera (AxioCam HR, Carl Zeiss, Göttingen, Germany). For fluorescence quantification, a KS imaging software system (Carl Zeiss, Vision GmbH, Hallbergmoos, Germany) was used. Throughout the study parameters such as objective lenses, excitation and emission filters and exposure time were kept constant to maintain uniformity.

The presence of tumor tissue was confirmed through the fluorescence detection of DiO, using a filter set consisting of a 450-490 nm band-pass excitation filter and a 515-565 nm band-pass emission filter. For fluorescence imaging of PVP-hypericin a filter set with a 510-560 nm bandpass excitation filter and a $590 \mathrm{~nm}$ long-pass emission filter was used. The filter set used for PpIX fluorescence imaging consisted of a $395-440 \mathrm{~nm}$ band-pass excitation filter and a $590 \mathrm{~nm}$ longpass emission filter. Rapid observation and electronic image storage avoided significant photobleaching of the fluorescence signal. In each tissue section, regions of interest were delineated and within that region the fluorescence was quantified. Corrections were made for autofluorescence, by subtracting autofluorescence levels of each tissue layer (urothelium, submucosa, muscle) obtained from control animals. After examination of the fluorescence, bladder sections were stained with standard hematoxylin and eosin (H\&E) staining for histological examination. 


\section{Results}

In the present study the biodistribution of both PVP-hypericin and HAL induced PpIX was compared in normal and tumor bearing rat bladders. After instillation, the induced fluorescence was measured in the different layers of the bladder (urothelium, submucosa, muscle) and further quantified using image analysis software.

Figures 1 and 2 show typical fluorescence micrographs of $5 \mu \mathrm{m}$ bladder sections after instilling PVP-hypericin (Fig. 1a, c) or HAL (Fig. 2a, c) in normal (Fig. 1a; Fig 2a) or tumor bearing bladders (Fig. 1c; Fig 2c). AY-27 cells could easily be visualized by pre-incubating them in vitro with the green fluorescent carbocyanine dye $\mathrm{DiO}$, and interestingly, a good correlation between areas consisting of malignant urothelium loaded with the green fluorescent $\mathrm{DiO}$ and the localization of PVP-hypericin- or PpIX-related red fluorescence was found (Fig 1e, f; Fig 2e, f).

Overall, PVP-hypericin related fluorescence was strong, whereas accumulated PpIX showed a weaker fluorescence signal. Because of this difference, a lower gain of sensitivity (gain 2) and a higher gain of sensitivity (gain 3) was used for PVP-hypericin and PpIX imaging, respectively.

In comparison to the epithelial cell layers visualized by H\&E staining (Fig. 1b) it can be seen that, PVP-hypericin penetrated the normal urothelium only very limitedly. Only the first two epithelial cell layers show bright fluorescence, whereas the deeper layers virtually do not exhibit any fluorescence signal. On the other hand PVP-hypericin migrated well throughout all cell layers of the malignant urothelium, resulting in a uniform distribution of the compound in all cell layers of the epithelium (Fig. 1d). Conversely, HAL-induced PpIX displayed a homogeneous distribution in both, malignant and normal urothelium (Fig. 2a, c).

Quantification of the fluorescence signal in sections of normal and tumor bearing bladders after PVP hypericin or HAL treatment revealed that PVP-hypericin (Fig. 3a) accumulated on average about 3.5-fold more in malignant urothelial tissue as compared to normal urothelium, whereas PpIX accumulated to the same extent in malignant and normal urothelium, both after intra-bladder instillation of 8 or $16 \mathrm{mM} \mathrm{HAL} \mathrm{(Fig.} \mathrm{3b,} \mathrm{c).} \mathrm{In} \mathrm{order} \mathrm{to} \mathrm{assess} \mathrm{the} \mathrm{selectivity} \mathrm{of}$ accumulation of PVP-hypericin and PpIX in the urothelium of normal bladders and tumor bladders, (i) the ratio of the relative fluorescence present in the urothelium $\left(\mathbf{F}_{\mathbf{U}}\right)$ to the one present in the submucosa $\left(\mathbf{F}_{\mathbf{S M}}\right)$, and (ii) the ratio of the relative fluorescence present in the urothelium $\left(\mathbf{F}_{\mathbf{U}}\right)$ to the one present in the muscle $\left(\mathbf{F}_{\mathbf{M}}\right)$ were calculated. The results are presented in Table 1

and show that both PVP-hypericin and PpIX accumulated selectively in the urothelium with a tumor-to-muscle ratio of 30.6 for PVP-hypericin and 3.7 to 8.3 for 16 and $8 \mathrm{mM} \mathrm{HAL}$, respectively. 


\section{Discussion}

In the present in vivo study the biodistribution of PVP-hypericin and HAL-induced PpIX in both healthy rat bladders and in an orthotopic rat bladder tumor model was compared. For that purpose we instilled rats intravesically with PVP-hypericin $(30 \mu \mathrm{M})$ or HAL $(8,16 \mathrm{mM})$ three days after tumor inoculation with concentrations that correspond to the ones typically used in the urological clinic $[5,8,9,28-30]$. The results show that administration of either of the compounds resulted in an increased uptake (PVP-hypericin) or production (PpIX) of the photosensitizers in normal or malignant urothelium as compared with the deeper tissue layers, i.e. submucosa and muscle layer.

The uptake of 5-ALA or its derivative HAL and subsequent conversion to the photoactive compound PpIX, depends on a broad range of metabolic and tissue specific factors [18], but also on the administration route, concentration and instillation time [31]. In this study a similar procedure was applied that was used before by another group investigating the biodistribution of HAL-induced PpIX in the orthotopic rat bladder tumor model for the first time [27]. Our results are in line with the published data with regard to the similar PpIX accumulation in normal and tumor urothelium that are seen when 8 or $16 \mathrm{mM} \mathrm{HAL}$ is instilled [27]. In contrast, the tumor-to-muscle ratio was previously found equal at both concentrations, whereas in our study the tumor-tomuscle ratio is twice as high when using $8 \mathrm{mM} \mathrm{HAL}$ as compared to $16 \mathrm{mM} \mathrm{HAL}$.

A similar PpIX fluorescence in malignant urothelium after 8 and $16 \mathrm{mM} \mathrm{HAL}$ administration, does however not necessarily guarantee a similar PDT efficacy. For instance, PDT after $16 \mathrm{mM}$ HAL resulted mostly in bladder wall necrosis without tumor eradication, whereas with $8 \mathrm{mM} \mathrm{HAL}$ and the same light conditions used, there was effective tumor damage without any effect on the bladder wall [27].

Of interest, a follow-up study by the same group using a gross tissue extraction method, indicated that after $8 \mathrm{mM} \mathrm{HAL}$ the PpIX concentration in tumor bladders was significantly higher than with $16 \mathrm{mM} \mathrm{HAL} \mathrm{[32],} \mathrm{and} \mathrm{it} \mathrm{was} \mathrm{concluded} \mathrm{that} \mathrm{PpIX-fluorescence} \mathrm{as} \mathrm{measured} \mathrm{by}$ fluorescence microscopy does not always mirror linearly drug concentrations. Besides, also the subcellular localization of PpIX critically depends on the concentration of HAL instilled. Importantly, this localization affects the damage to specific cellular organelles and therefore the PDT efficacy [32]. Hence, predicting the photodynamic therapeutic outcome based exclusively on the HAL-induced PpIX fluorescence observed appears to be difficult. This is especially problematic when it comes to potentially photo-active amounts of photosensitizer present in the detrusor muscle resulting in fibrotic and contracted bladder with upper tract obstruction [33,34]. For obvious reasons, these adverse effects should be thoroughly avoided. 
The biodistribution of PVP-hypericin in the different layers of the orthotopic tumor bearing rat urinary bladder correlates well with the one observed in similar conditions when hypericin is formulated in the presence of human serum albumin (HSA) [35]. The fluorescence intensity ratios of the bladder urothelial tumor to both submucosa and muscle are comparable in both studies. As a consequence it can be expected that the outcome of whole bladder wall PDT in an in vivo model will largely coincide with the results previously obtained using HSA-hypericin [36]. In contrast with HAL, when using PVP-hypericin there seems to exist a good correlation between the fluorescence present in the different layers and the local damage photodynamically induced.

An interesting observation is the fact that HSA-hypericin was not selectively taken up by malignant as compared to normal urothelium [35], whereas PVP-hypericin in this study is taken up about a 3- to 4-fold more in malignant tissue than in benign urothelium. Presently, we cannot account for this difference, but definitely the present preclinical findings with PVP-hypericin support very well the clinical results obtained with both HSA- and PVP-hypericin that detect NMIBC with a high sensitivity and good specificity [8-10,28]. For example, in case of PVPhypericin used for the fluorescence-based diagnosis of bladder cancer in patients, a sensitivity ranging from $85 \%$ (dysplasia) to $100 \%$ (CIS, T1 and T2) and a specificity of $53 \%$ was found [28].

Whether the difference in accumulation of PVP-hypericin between malignant tissue and benign urothelium will also result in a differential PDT effect, is yet unknown. However, even if not entirely the case, it is known that PDT induced urothelial damage regenerates in a short time period without significant alterations to the bladder wall $[37,38]$.

In conclusion, we have shown that after instillation of a normal and an orthotopic tumor bearing rat urinary bladder, PVP-hypericin and HAL-induced PpIX are selectively present in the bladder urothelial tumors. Overall, the accumulation in the urothelium vs. the underlying tissues is much better for PVP-hypericin than for PpIX. The restrictive distribution in the urothelial tumor suggests that by using appropriate light doses, PDT with PVP-hypericin should produce a selective urothelial tumor destruction without causing damage to the muscle layer. Besides being an effective diagnostic tool, PVP-hypericin therefore appears to have great potential as a photodynamic agent against non-muscle-invasive bladder cancers.

\section{Acknowledgments}

This work was supported by grants awarded by "Fonds voor Wetenschappelijk OnderzoekVlaanderen (F.W.O-Vlaanderen), by the K.U.Leuven (onderzoekstoelage) and Sanochemia Pharmazeutika AG (Austria).

\section{Disclosures}

None 


\section{Tables}

Table 1: Selectivity of the accumulation of PVP-hypericin or HAL-induced PpIX, expressed as (i) the ratio of the relative fluorescence present in the urothelium $\left(\mathbf{F}_{\mathbf{U}}\right)$ to the one present in the submucosa $\left(\mathbf{F}_{\mathbf{S M}}\right)$, and (ii) as the ratio of the relative fluorescence present in the urothelium $\left(\mathbf{F}_{\mathbf{U}}\right)$ to the one present in the muscle $\left(\mathbf{F}_{\mathbf{M}}\right)$.

\begin{tabular}{|l|c|c|c|c|c|c|}
\hline & \multicolumn{2}{|c|}{ PVP-hypericin } & \multicolumn{2}{c|}{$\begin{array}{c}\text { HAL induced PpIX } \\
\text { (16mM) }\end{array}$} & \multicolumn{2}{c|}{$\begin{array}{c}\text { HAL-induce PpIX } \\
\text { (8mM) }\end{array}$} \\
\cline { 2 - 7 } & NB $^{\mathbf{a}}$ & TB $^{\mathbf{b}}$ & NB & TB & NB & TB \\
\hline $\mathrm{F}_{\mathbf{u}} / \mathrm{F}_{\mathbf{s m}}$ & 34.2 & 12.8 & 3.8 & 2.8 & 6.6 & 3.6 \\
\hline $\mathrm{F}_{\mathbf{u}} / \mathrm{F}_{\mathbf{m}}$ & 47.5 & 30.6 & 8.6 & 3.7 & 7.6 & 8.3 \\
\hline
\end{tabular}

${ }^{a}$ normal bladder; ${ }^{\mathbf{b}}$ tumor bladder 


\section{Figure Legends}

Fig.1: Localization of PVP-hypericin in normal urothelium and urothelial tumors. Fluorescence photomicrographs of PVP-hypericin ( $30 \mu \mathrm{M}, 2 \mathrm{~h}) 3$ days after tumor inoculation in normal (a) and tumor bearing rat bladders (c), and corresponding H\&E stainings (b, d) of $5 \mu \mathrm{m}$ frozen tissue sections. Visualization of the malignant epithelium by $\mathrm{DiO}(\mathrm{e})$ and overlay of DiO fluorescence and PVP-hypericin fluorescence (f). $(a, c)$ gain $=2$, exposure $=200$, original magnification $=200 \mathrm{X}$

Fig.2: Localization of $\mathrm{PpIX}$ in normal urothelium and urothelial tumors. Fluorescence photomicrographs of HAL induced PpIX ( $8 \mathrm{mM}, 2 \mathrm{~h}) 3$ days after tumor inoculation in normal (a) and tumor bearing rat bladders (c), and corresponding H\&E stainings (b, d) of $5 \mu \mathrm{m}$ frozen tissue sections. Visualization of the malignant epithelium by $\mathrm{DiO}(\mathrm{e})$ and overlay of $\mathrm{DiO}$ fluorescence and PpIX fluorescence $(f)$. $(a, c)$ gain $=3$, exposure $=200$, original magnification $=200 X$

Fig.3: Quantification of (a) PVP-hypericin $(30 \mu \mathrm{M})$ and (b, c) HAL (8, $16 \mathrm{mM})$ induced PpIX fluorescence in different layers of the bladder. In each graph the fluorescence intensity in normal and tumor bearing bladders is compared. Means \pm SD are shown 


\section{References}

1. Kirkali Z, Chan T, Manoharan M, Algaba F, Busch C, Cheng L, Kiemeney L, Kriegmair M, Montironi R, Murphy WM (2005) Bladder cancer: Epidemiology, staging and grading, and diagnosis. Urology International Consultation on Bladder Tumors 66:4-34.

2. Kausch I, Doehn C, Jocham D (2006) Recent improvements in the detection and treatment of nonmuscle-invasive bladder cancer. Expert Rev Anticancer Ther 6:13011311.

3. Hendricksen K, Witjes JA (2007) Current strategies for first and second line intravesical therapy for nonmuscle invasive bladder cancer. Curr Opin Urol 17:352-357.

4. Hungerhuber E, Stepp H, Kriegmair M, Stief C, Hofstetter A, Hartmann A, Knuechel R, Karl A, Tritschler S, Zaak D (2007) Seven years' experience with 5-aminolevulinic acid in detection of transitional cell carcinoma of the bladder. Urology 69:260-264.

5. Jocham D, Stepp H, Waidelich R (2008) Photodynamic diagnosis in urology: state-of-theart. Eur Urol 53:1138-1148.

6. Kubin A, Wierrani F, Burner U, Alth G, Grunberger W (2005) Hypericin--the facts about a controversial agent. Curr Pharm Des 11:233-253.

7. Kiesslich T, Krammer B, Plaetzer K (2006) Cellular mechanisms and prospective applications of hypericin in photodynamic therapy. Curr Med Chem 13:2189-2204.

8. D'Hallewin MA, De Witte PA, Waelkens E, Merlevede W, Baert L (2000) Fluorescence detection of flat bladder carcinoma in situ after intravesical instillation of hypericin. J Urol 164:349-351.

9. D'Hallewin MA, Kamuhabwa AR, Roskams T, De Witte PA, Baert L (2002) Hypericinbased fluorescence diagnosis of bladder carcinoma. BJU Int 89:760-763.

10. Sim HG, Lau WK, Olivo M, Tan PH, Cheng CW (2005) Is photodynamic diagnosis using hypericin better than white-light cystoscopy for detecting superficial bladder carcinoma? BJU Int 95:1215-1218.

11. Pytel A, Schmeller N (2002) New aspect of photodynamic diagnosis of bladder tumors: fluorescence cytology. Urology 59:216-219.

12. Fu CY, Ng BK, Razul SG, Chin WW, Tan PH, Lau WK, Olivo M (2007) Fluorescence detection of bladder cancer using urine cytology. Int J Oncol 31:525-530.

13. Van De Putte M, Roskams T, Bormans G, Verbruggen A, De Witte PA (2006) The impact of aggregation on the biodistribution of hypericin. Int $\mathrm{J}$ Oncol 28:655-660.

14. Kubin A, Loew HG, Burner U, Jessner G, Kolbabek H, Wierrani F (2008) How to make hypericin water-soluble. Pharmazie 63:263-269.

15. Liu J, Saw CL, Olivo M, Sudhaharan T, Ahmed S, Heng PW, Wohland T (2009) Study of interaction of hypericin and its pharmaceutical preparation by fluorescence techniques. $J$ Biomed Opt 14:014003.

16. Leveckis J, Burn JL, Brown NJ, Reed MW (1994) Kinetics of endogenous protoporphyrin IX induction by aminolevulinic acid: preliminary studies in the bladder. J Urol 152:550553.

17. Van Hillegersberg R, Van den Berg JW, Kort WJ, Terpstra OT, Wilson JH (1992) Selective accumulation of endogenously produced porphyrins in a liver metastasis model in rats. Gastroenterology 103:647-651. 
18. Rodriguez L, Batlle A, Di Venosa G, Battah S, Dobbin P, Macrobert AJ, Casas A (2006) Mechanisms of 5-aminolevulinic acid ester uptake in mammalian cells. $\mathrm{Br} \mathrm{J}$ Pharmacol 147:825-833.

19. Schmidbauer J, Witjes F, Schmeller N, Donat R, Susani M, Marberger M (2004) Improved detection of urothelial carcinoma in situ with hexaminolevulinate fluorescence cystoscopy. J Urol 171:135-138.

20. Fotinos N, Campo MA, Popowycz F, Gurny R, Lange N (2006) 5-Aminolevulinic acid derivatives in photomedicine: Characteristics, application and perspectives. Photochem Photobiol 82:994-1015.

21. Kamuhabwa A, Agostinis P, Ahmed B, Landuyt W, van Cleynenbreugel B, van Poppel H, de Witte $P$ (2004) Hypericin as a potential phototherapeutic agent in superficial transitional cell carcinoma of the bladder. Photochem Photobiol Sci 3:772-780.

22. Berger AP, Steiner H, Stenzl A, Akkad T, Bartsch G, Holtl L (2003) Photodynamic therapy with intravesical instillation of 5-aminolevulinic acid for patients with recurrent superficial bladder cancer: a single-center study. Urology 61:338-341.

23. Kriegmair M, Waidelich R, Lumper W, Ehsan A, Baumgartner R, Hofstetter A (1995) Integral photodynamic treatment of refractory superficial bladder cancer. J Urol 154:13391341.

24. Pervaiz S, Olivo M (2006) Art and science of photodynamic therapy. Clin Exp Pharmacol Physiol 33:551-556.

25. Xiao Z, McCallum TJ, Brown KM, Miller GG, Halls SB, Parney I, Moore RB (1999) Characterization of a novel transplantable orthotopic rat bladder transitional cell tumour model. Br J Cancer 81:638-646.

26. Kamuhabwa AA, Cosserat-Gerardin I, Didelon J, Notter D, Guillemin F, Roskams T, D'Hallewin MA, Baert L, de Witte PA (2002) Biodistribution of hypericin in orthotopic transitional cell carcinoma bladder tumors: implication for whole bladder wall photodynamic therapy. Int J Cancer 97:253-260.

27. El Khatib S, Didelon J, Leroux A, Bezdetnaya L, Notter D, D'Hallewin M (2004) Kinetics, biodistribution and therapeutic efficacy of hexylester 5-aminolevulinate induced photodynamic therapy in an orthotopic rat bladder tumor model. J Urol 172:2013-2017.

28. Kubin A, Meissner P, Wierrani F, Burner U, Bodenteich A, Pytel A, Schmeller N (2008) Fluorescence diagnosis of bladder cancer with new water soluble hypericin bound to polyvinylpyrrolidone: PVP-hypericin. Photochem Photobiol 84:1560-1563.

29. Jichlinski P, Guillou L, Karlsen SJ, Malmstrom PU, Jocham D, Brennhovd B, Johansson E, Gartner T, Lange N, van den Bergh H, Leisinger HJ (2003) Hexyl aminolevulinate fluorescence cystoscopy: new diagnostic tool for photodiagnosis of superficial bladder cancer--a multicenter study. J Urol 170:226-229.

30. Malmstrom PU, Hedelin H, Thomas YK, Thompson GJ, Durrant H, Furniss J (2009) Fluorescence-guided transurethral resection of bladder cancer using hexaminolevulinate: analysis of health economic impact in Sweden. Scand J Urol Nephrol 43:192-198.

31. Gronlund-Pakkanen S, Wahlfors J, Makinen K, Pakkanen TM, Talja M, Ala-Opas M, Alhava E, Moore RB (2002) The fluorescence biodistribution and kinetics of aminolevulinic acid induced protoporphyrin IX in the bladder of a rat model with orthotopic urothelial carcinoma. J Urol 167:1848-1853.

32. Berrahmoune S, Fotinos N, Bezdetnaya L, Lange N, Guedenet JC, Guillemin F, D'Hallewin MA (2008) Analysis of differential PDT effect in rat bladder tumor models according to concentrations of intravesical hexyl-aminolevulinate. Photochem Photobiol Sci 7:1018-1024. 
33. Manyak MJ (1991) Photodynamic therapy: principles and urologic applications. Semin Urol 9:192-202.

34. Harty JI, Amin M, Wieman TJ, Tseng MT, Ackerman D, Broghamer W (1989) Complications of whole bladder dihematoporphyrin ether photodynamic therapy. J Urol 141:1341-1346.

35. Kamuhabwa AA, Roskams T, Baert L, De Witte PA (2003) Microscopic quantification of hypercin fluorescence in an orthotopic rat bladder tumor model after intravesical instillation. Int J Oncol 22:933-937.

36. Kamuhabwa AA, Roskams T, D'Hallewin MA, Baert L, Van Poppel H, de Witte PA (2003) Whole bladder wall photodynamic therapy of transitional cell carcinoma rat bladder tumors using intravesically administered hypericin. Int J Cancer 107:460-467.

37. Pope AJ, Bown SG (1991) The morphological and functional changes in rat bladder following photodynamic therapy with phthalocyanine photosensitization. J Urol 145:10641070.

38. Chang SC, MacRobert AJ, Bown SG (1996) Photodynamic therapy on rat urinary bladder with intravesical instillation of 5-aminolevulinic acid: light diffusion and histological changes. J Urol 155:1749-1753.
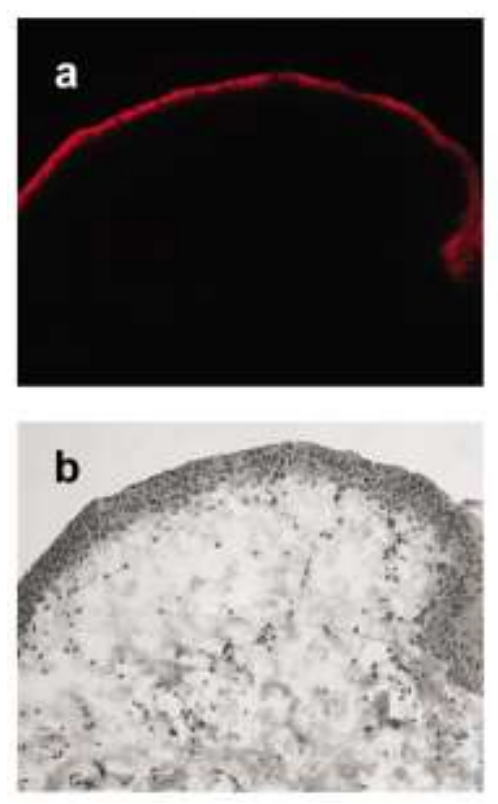
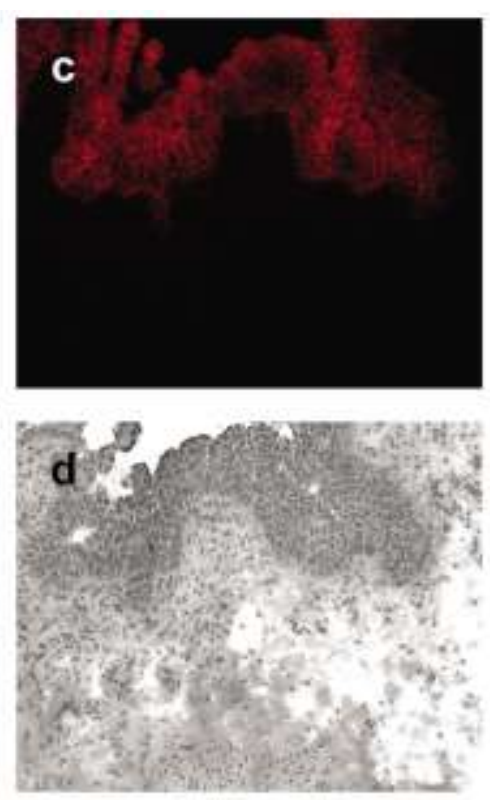
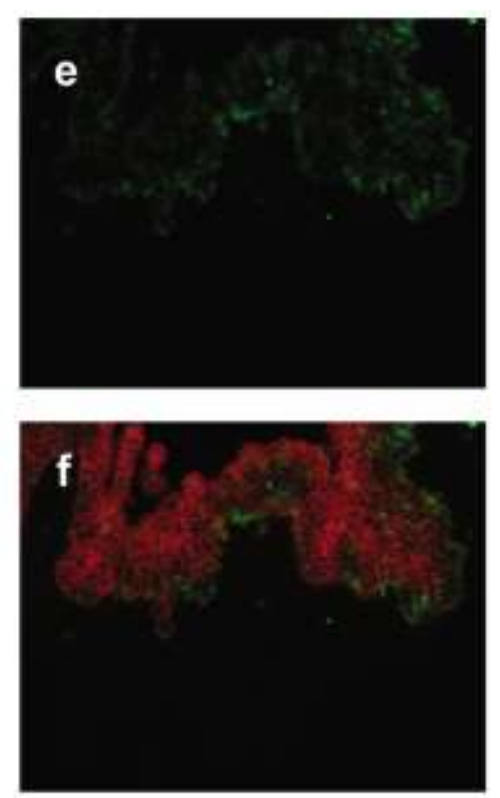

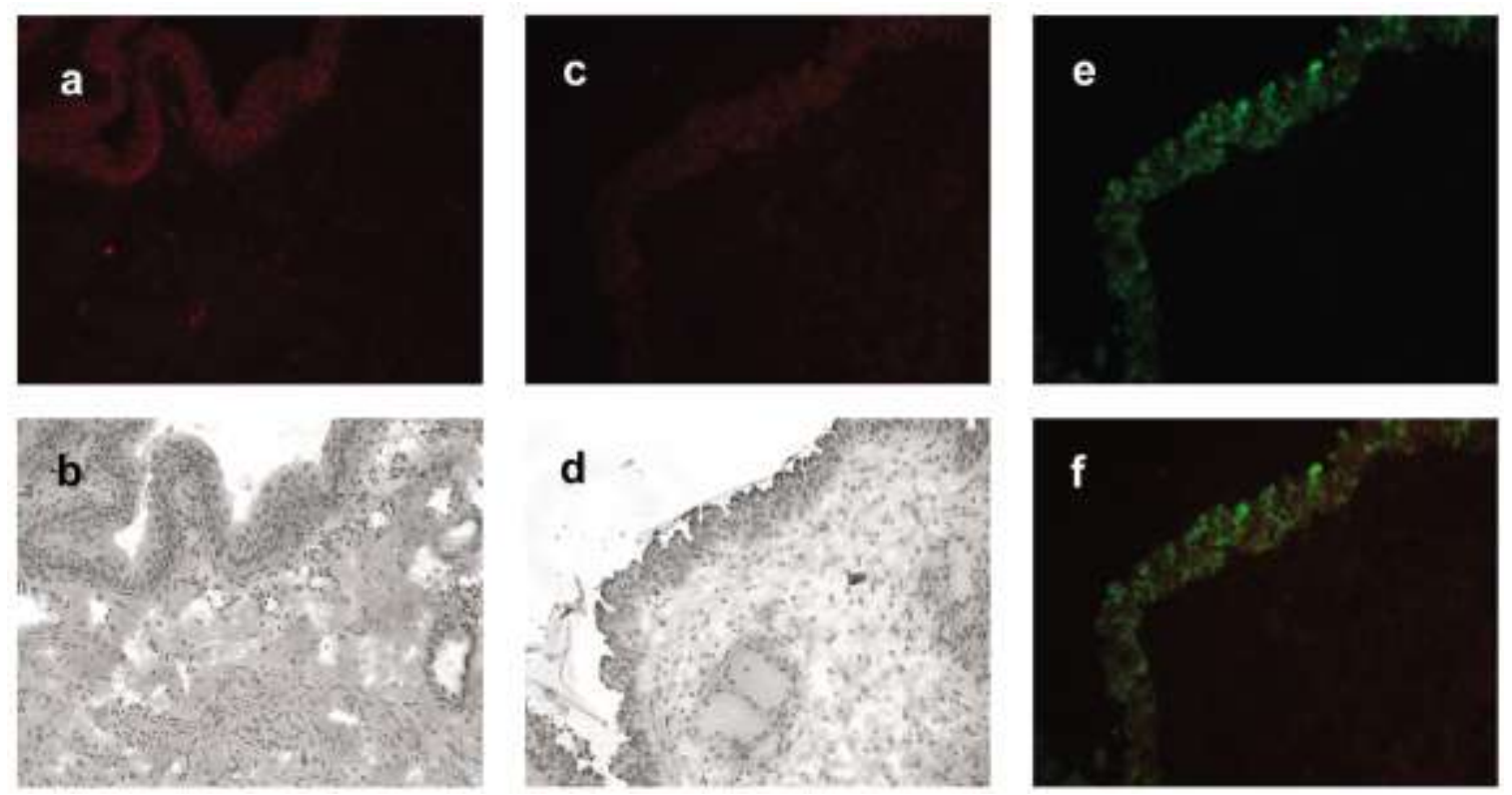

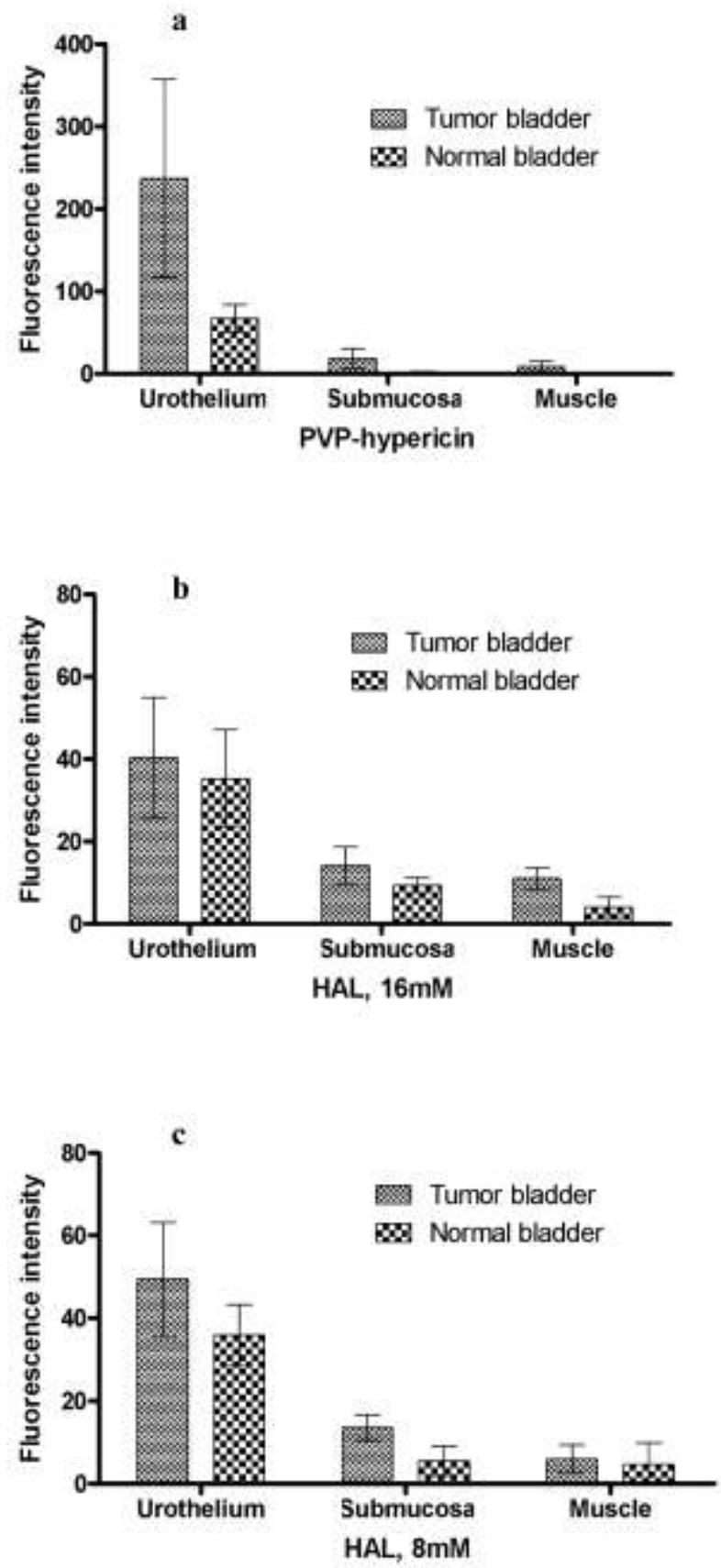